\title{
How to promote better care of elderly patients with multi-morbidity in Europe: A Swedish example
}

\author{
Anne Ekdahl
}

\section{Linköping University Post Print}

N.B.: When citing this work, cite the original article.

Original Publication:

Anne Ekdahl, How to promote better care of elderly patients with multi-morbidity in Europe: A Swedish example, 2012, EUROPEAN GERIATRIC MEDICINE, (3), 2, 103-106. http://dx.doi.org/10.1016/j.eurger.2011.10.002

Copyright: Elsevier Masson http://www.elsevier-masson.fr/

Postprint available at: Linköping University Electronic Press http://urn.kb.se/resolve?urn=urn:nbn:se:liu:diva-78277 
Title page:

How to promote better care of elderly patients with multi-morbidity in Europe: A Swedish example

Anne W. Ekdahl, MD 1,2

e-mail: anne.ekdahl@lio.se, 0046738484250

1 Department of Geriatric Medicine, Vrinnevi Hospital, 60182 Norrköping, Sweden

2 Department of Social and Welfare Studies, Faculty of Health Sciences, Linköping

University, Sweden 


\section{Abstract}

How to improve the care of elderly patients with multi-morbidity, regardless of borders between medical specialities and professions, starting from the patients' point of view and ending with a powerful policy document with impact on the political system. A document written by the Swedish Association of Geriatric Medicine, the Swedish Association of General Practice and the Swedish Association of Internal Medicine.

\section{Background}

In Sweden — as in all European countries - the population is old and growing elderly. Of the 9.6 million inhabitants, 494,000 people (5.1\%) are aged 80 and over, and 2,571,300 (26\%) are aged 65 and over (1). The largest increase is expected during the next decade, among the oldest persons. At the same time, the number of working-age people, those aged 20-64, will increase by just half that rate, meaning fewer people to provide for and take care of the elderly (1).

This is a challenge for society economically, with high costs for pensions and health care; politically, with the high proportion of elderly voters (in Sweden, 33\%) (1); and in matters of quality of care for the elderly, with a health care system more adapted to take care of patients with one or a few illnesses, rather than elderly patients with multi-morbidity, who instead receive fragmented care not adapted to their needs (2).

Due to these challenges there is a growing political interest in better care for the elderly. Sometimes one hears different (more or less easy) political solutions as to how to solve the problems. These suggestions often arise out of politicians' personal experiences or as a result of information collected in a not-systematic way, with the risk of lack of consistency and inadequate coverage of the broad aspects of care of the elderly. 


\section{How did it all start?}

One day, listening to a well-known Swedish politician (a doctor, too, by the way) I once again in her speech heard of some 'easy solutions'. After her talk I approached her and told her that I very much approved of her efforts to create a better care system for elderly residents. I said that I thought her suggestions sounded very good, but that I was afraid that they would not work when trying to realise them. Her response was: How can we as politicians know which changes to try to make in today's healthcare, when you doctors in the different specialities tells us different things? She had a very good point. First, I thought that doctors from different specialities were unlikely to succeed in developing a joint policy document, considering all the small battles and wars of the past decades over competence - who is going to do what and where - but after some thought I decided to give it a try. As president of the Swedish Association of Geriatric Medicine at that time, I contacted the presidents of the Swedish General Practitioners (GPs) and Internists. To my pleasure, both showed interest. The GPs were interested at once, and their president would participate herself in the work-the internists delegated the question to a board member who later left, but when a new president took over and he himself joined the work, the process was able to get under way. Two more members were recruited to the working group, the vice president of the geriatricians association and the advisor of home-care for the GPs, for a total of five persons.

During our work with the policy document, it was later showed, finding meeting times was actually harder than grappling with the contents of the document. We were very focused on the patients' perspective, and that helped us through most of our small disagreements. Of course, we had to negotiate and each of us gave in a little.

We started with a strong focus on the whole situation of life (getting well-cooked meals, be able to get out in the fresh air, feeling secure and living a life with dignity) — not the health 
care. Then we stressed the need for situation-oriented care with a holistic view-rather than a working in multi-professional teams, and of course, with gerontological and geriatric competence. In one point we had a structural focus, too: the need of special acute wards designed for elderly patients, with the competence of working with elderly people and in teams.

After 4 or 5 meetings the document was completed (3) and after approval of our three medical associations, we were able to distribute the document to other medical associations and our National Medical Bulletin (4), politicians, senior citizens organisations and other professions involved in the care of the elderly. The interest from politicians was scarcely overwhelming at the beginning — but the senior citizens liked the proposals. We (mostly the president of the GPs and I) toured around the country giving presentations. Then, with our document as a base, several senior citizens organisations wrote their own joint document. This work resulted in another policy document (not translated into English) (5), in no way in conflict with our first document created by the doctors associations, but perhaps stressing more the need of multi-professional teams adapted to each patient's needs and geriatric competence. The senior citizens document strengthens the doctors document a put further pressure on the politicians to create a better care for the elderly with multi-morbidity. Below is the doctors' policy document written by the Swedish Association of General Practitioners (SAGP), Swedish Association of Geriatric Medicine (SAGM) and Swedish Association of Internal Medicine (SAIM). The is document slightly adapted to fit in the format of a scientific journal. 


\footnotetext{
${ }^{1}$ For scientific and statistical purposes, the following specification has been used: Persons aged 75 years and above, who have three or more diagnoses in three or more different diagnostic groups according to the classification system ICD 10, and who have been hospitalised three or more times during the past year.
}

\section{The policy document (translated from Swedish): Better care for elderly patients with multi-morbidity ${ }^{1}$}

Elderly patients with multi-morbidity are people who need care characterised by a holistic view, continuity and cooperation between different specialities and professions, and across organisational borders — care that would make life easier and more dignified for many patients and their relatives. It would also lead to reduced stress on the acute medical care system. This kind of care is already possible, but requires good geriatric expertise, a customised reimbursement system, improved information transfer and customised training.

\section{Definition}

Elderly patients with multi-morbidity are in this document defined as elderly people with complex needs of care, a care that demands tight cooperation between hospital care, primary care (family physicians and district nurses) and the care provided by the municipalities (home-help services).

\section{Basic needs}

First and foremost, elderly patients with multi-morbidity need living conditions and daily care which reduce the risk of further deterioration and allow for a dignified life. Most important are a feeling of security in everyday life, the opportunity for social interaction, well-cooked and -served food and good personal hygiene, as well as access to suitable outdoor activities. In addition to these requests come the health care needs to be attended to. 


\section{Goals for health care}

- Every elderly person with multi-morbidity should have designated principal caregivers, both within the municipality's home care service and in the primary care system (home-help provider, district nurse and family physician).

- The elderly patient with multi-morbidity with greater needs should also have an appointed inpatient care provider with geriatric expertise, for inpatient care.

- For every elderly patient with multi-morbidity, a multidisciplinary and multiprofessional team should be formed, based on the needs of the individual patient.

- Responsible family physicians or geriatricians, or other specialists with appropriate geriatric expertise, should, in agreement with the primary care system, have prompt access to consultations with other medical specialties, this, not least, to reduce the need for the elderly person with multi-morbidity to come to the emergency or outpatient hospital departments.

- When in need of inpatient care, elderly patients with multi-morbidity shall have a special 'fast track', that is, hospitalisation should be on a special ward through a direct contact between primary care and the geriatric department, and not through the emergency department.

- Every elderly person with multi-morbidity shall—when needed—have access to situation-based ${ }^{2}$ home care.

In figure 1 we have suggested an overall organisation map to meet the needs of elderly with multi-morbidity.

\footnotetext{
${ }^{2}$ Situation-based care: Care based on a holistic view of the person's accumulated situation of life (physical, psychological, social and functional) and in balance with accessible resources for care.
} 


\section{To achieve these goals, the following changes are needed:}

- adaptation of the reimbursement systems, so that a situation-based approach is encouraged and enabled,

- establishment of systems that allow for safe and rapid transfer of information, and

- provision of resources for participation in continuing medical education customised for the needs of elderly patients with multi-morbidity and their care providers.

\section{Background to today's health-care of elderly with multi-morbidity}

In most of the Swedish health care organisation a disease- or diagnosis-oriented approach has developed over the years. This is an appropriate model for patients in need of occasional visits, but does not fit the needs of the elderly with multi-morbidity. They need a situationbased approach. For example, this is evident in situations when the goal of care is shifted from efforts to restore full health to efforts to achieve best possible well-being, and finally to achieve a good end of life. The point at which the transition between the different needs occurs for an individual person is difficult to predict and is influenced by many factors. The concept of multi-morbidity means that it can be difficult or impossible to determine which of the diseases causes a person's perceived problems. The different illnesses influence each other, and an optimal treatment for each of the diagnoses can, taken together, constitute a medical risk, that is, in terms of poly-pharmacy. The biological age of the multi-morbid elderly patient contributes to reduced bodily function, including that of kidneys and liver, which complicates the treatment. In addition, declining cognitive function can sometimes make it difficult for patients to explain their symptoms, evaluate their health and to undergo investigations and treatments.

The home situation is of great importance in situation-oriented care. What opportunities for 
home care, and what individual concerns, expectations and fears are there? What is the attitude of the family members?

All of the above-mentioned conditions explain why elderly patients with multi-morbidity have a special need for personalised, safe, wide-spectred, coordinated and continuous health carecare in which the holistic and generalist perspectives are particularly important and also minimise the need for repeated, unplanned inpatient care periods. This approach requires a flexible organisation, usually with a multidisciplinary and multi-professional team, and with solutions that can function across the borders of different organisations. The multi-morbid elderly patient should feel that he/she is being chosen for particular care. Together with their families, they must be provided with knowledge concerning what they can expect from this care, not least at the end of life.

\section{Prognosis of the number of elderly people with multi-morbidity in}

\section{Sweden}

To determine the number of elderly people with multi-morbidity, we have used the definition suggested by the Swedish National Centre of Epidemiology in 2001: 'A person over 75 years of age who has been hospitalised three or more times in the last 12 months and has three or more diagnoses in their medical records according to the International Classification of Diseases (ICD-10)'(6). This is a strictly epidemiological definition with its limitations based on times of hospitalisation. Based on this definition, elderly people with multi-morbidity have, in several studies in Sweden, been shown to be around $7 \%$ of the population above 75 years; the proportion has remained fairly stable for the past 10 years. These patients consume $19 \%$ of all in-hospital care in Sweden (7). In figure 2 you can see the marked rise tin the population after 2020 . 


\section{Effects of the policy document}

As the inhabitants in Sweden are old, senior citizens have a lot of votes (2.5 out of 7.5 million, or 33\%), and both their and our policy documents have received a lot of political interest since they were published in autumn 2009. In our last general election in September 2010 there were a lot of promises, and there was very much focus on the elderly, and in part, on geriatric medicine.

Some of the initiatives taken during the past year (autumn 2010 and spring 2011) by the government include

- The Swedish National Board of Health and Welfare was requested to write a report and give suggestions on how to improve gerontological and geriatric competence in Swedish health care; the report was finished March 2011. Some of the suggestions made to government in the report were to increase the education rate of new geriatricians, to improve geriatric and gerontological education during medical school, to look over the system of reimbursement in geriatric care not supporting a holistic view and to enhance grants to geriatric research (8).

- The minister of health granted 25 million Euros per year over three years to activate the use of two registers, one with a focus on palliative care and one with a focus on registration of risk of falls, malnutrition and pressure sores.

- The sum of 25 million Euros was granted to 19 projects to test new methods of taking care of elderly people in daily clinical work, focusing on cooperation between municipalities (taking care of elderly people living at home and in nursing homes) and the county councils (taking responsibility for the health care). 
- A special officer was appointed to coordinate the work of ensuring better care of elderly residents in Sweden, with a position directly under the minister of children and old age in the Department of Health and Social Affairs. One of her tasks is to look for good examples of geriatric care, and to make suggestions of how to improve the reimbursement system and to find better ways to identify frail elderly residents.

Of course, many of these initiatives would have been taken without our policy document, but we are sure that it has been an important guide, and it has very often been referred to by politicians and high officials. It does not seem that the interest has diminished through recent months_-quite the contrary.

We all have to realise that there are no easy solutions or quick fixes to create better care for elderly people with multi-morbidity. It is necessary to work in multi-professional teams, to have a holistic view, to take the time to communicate with the patient and all involved — and to have geriatric competence.

\section{Acknowledgements}

To Arne Sjöberg, vice-president of the Swedish Association of Geriatric Medicine;

To Annika Eklund-Grönberg, president of the Swedish Association of General Practice.

To Mikael Köhler, president of the Swedish Association of Internal Medicine;

To Sonja Modin, chair and advisor for home care, the Swedish Association of General Practice 


\section{References:}

1. The future population of Sweden 2010-2060. Available at: http://www.scb.se/Statistik/BE/BE0401/2010I60/BE0401_2010I60_SM_BE18SM1001.pdf. Statitics Sweden. 2008;BE 18 SM 1001.

2. Norris SL, High K, Gill TM, Hennessy S, Kutner JS, Reuben DB, et al. Health Care for Older Americans with Multiple Chronic Conditions: A Research Agenda. Journal of the American Geriatrics Society. 2008;56(1):149-59.

3. Ekdahl A, Eklund-Grönberg A, Kohler M, Sjöberg A, Modin S. Better care for elderly patients with multi-morbidity — a policy document. Available at: http://www.slf.se/upload/Specforeningar/SGF/Dokument\%20h\%c3\%b6st\%2009/Policydoku ment\%20sept\%2009.doc (In Swedish). 2009.

4. Eklund-Grönberg A, Köhler M, Ekdahl A, Modin S, Sjöberg A. A better care for elderly with comorbidity. Swedish Medical Bulletin. 2009;106(40):1512.

5. En vård värd samverkan (in Swedish). Available at:

[http://www.pro.se/PageFiles/32761/En\%20V\%C3\%A5rd\%20V\%C3\%A4rd\%20Samverkan. pdf. Senior citizens organisations in Sweden. 2010.

6. Gurner U, Thorslund M. Holistic perspective is needed in care of multiimpaired elderly. A proposal for structural change of the organization of care in the county of Stockholm. Läkartidningen. 2001;98(21):2596-602.

7. Ekerstad N, Carlsson P, Edberg A. Priorization of frail elderly in cardiological care - a medical, ethical and economical challenge [Rapport Prioriteringscentrum]:

Prioriteringscentrum; 2008 [updated 2008; cited 2008:4 January, 2008]; Available from: http://www.imh.liu.se/halso-ochsjukvardsanalys/prioriteringscentrum/publikationer/prioriteringscentrums-publikationerovrigt-publicerat-material/1.192868/2008.4.pdf. 
8. Ökad kompetens inom geriatrik och gerontologi - strategiskt viktiga problem och förslag till åtgärder (in Swedish):

http://wwwsocialstyrelsense/Lists/Artikelkatalog/Attachments/18282/2011-3-34pdf Swedish National Board of Health and Welfare. 2011. 




Figure 1. Organisation to meet the needs of elderly with co-morbidity

(n)

- not through ER or other clinics.
\end{abstract}




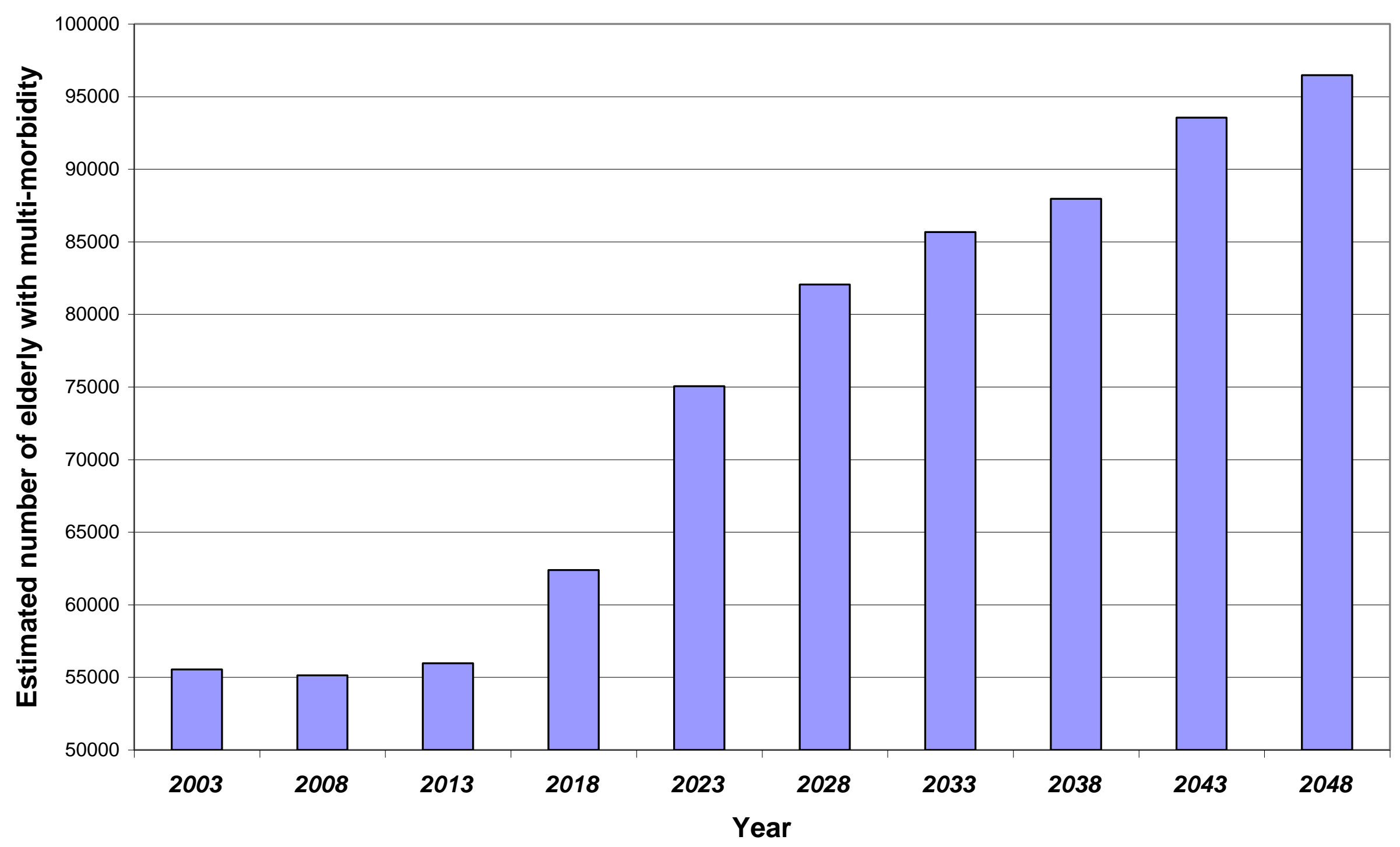

Figure 2: Population projection in Sweden according to the Swedish National Statistical Bureau 
Sweden, the 24th of September, 2011

\section{Author agreement:}

I the undersigned declare that this manuscript is original, has not been published before and is not currently being considered for publication elsewhere.

I understand that the Corresponding Author is the sole contact for the Editorial process. $\mathrm{He} / \mathrm{she}$ is responsible for communicating with the other authors about progress, submissions of revisions and final approval of proofs.

Anne Ekdahl 
Ethical statement

I declare that this article do not content anything that needs the approval of an Ethical Board.

Anne Ekdahl 